\title{
Evaluation of the Medical and Health System Reform in China: Based on the Fuzz Comprehensive Evaluation Method
}

\author{
Zhu Fengmei \\ Policy Research Center of the Ministry of Civil Affairs, Beijing, China
}

Email address:

fengmei.zhu@163.com

To cite this article:

Zhu Fengmei. Evaluation of the Medical and Health System Reform in China: Based on the Fuzz Comprehensive Evaluation Method. Journal of Health and Environmental Research. Vol. 4, No. 3, 2018, pp. 91-96. doi: 10.11648/j.jher.20180403.12

Received: May 15, 2018; Accepted: July 6, 2018; Published: August 1, 2018

\begin{abstract}
This paper aims to explore the application of the fuzzy comprehensive evaluation method in the evaluation of the medical and health system reform by establishing an evaluation index system. Index weights were determined by means of factor analysis and analytic hierarchy process (AHP), while fuzzy membership functions were used to determine the subordination grades of the evaluated objects on different indexes. Based on that, the fuzzy comprehensive evaluation results and comprehensive scores of 31 provinces, municipalities and autonomous regions in different subordination levels in China were obtained by constructing Multi-level Comprehensive Evaluation Model. The results indicated that the effect of the reform of the medical and health system was relevant to local economic development level to some extent, while both commonalities and differences exist in the results of comprehensive evaluation performance among different regions. To improve the performance of the medical and health system, practical and feasible reform measures need to be put forward based on local realities.
\end{abstract}

Keywords: Fuzzy Comprehensive Evaluation, Membership Function, AHP, Factor Analysis,

Medical and Health System Reform

\section{Introduction}

As of 2018, the new medical reform has been in progress for nine years. China's medical reform program, aiming at addressing difficulties and high expense in medical care, has realized institutionally full coverage of the whole population by the basic medical insurance through increasing the government's input into the healthcare and adhering to the principle of "giving subsidies to both supply and demand sides", with the new rural cooperative medical system (NCMS) even integrated with the medical insurance for urban residents (MIUR) in some areas. Statistics show that the proportion of public financing in China's total health expenditure has increased from $49.1 \%$ in 2008 to $65.8 \%$ in 2013. In the suggestions about the reform of county- and city-level public hospitals announced by the General Office of the State Council, substantive actions and targets were put forward compared with the previous ones [1, 2]. With reforms of the supply and demand sides advancing continuously, the effect of the implemented reform of the medical and health system and the fact whether the reform addresses the problems in accessing medical care for and reducing the medical burden of the masses have become key issues deserving attention.

\section{Materials and Methods}

\subsection{Selection of Indexes}

Since the new medical reform started in 2009, the World Health Organization (WHO) has designed a monitoring and evaluation framework for China's current medical and health system reform from a global perspective, which comprises a continuous progress of four stages (i.e., Input \& Process-Output-Result-Effect) to evaluate the effect of the medical and health system reform [3]. Besides, some research institutions, such as the research groups from the Institute of Population Research, Peking University and Shanghai Jiao Tong University, have also evaluated the effect of China's medical and health system reform in succession [4]. However, the existing evaluation frameworks and 
indexes mainly focus on the micro level but ignore the macro level, for example, such factors as the level of social and economic development in different regions as well as the economic burden of people for medical treatment are not taken into account. In this article, an index system is established based on three dimensions, i.e., social and economic conditions, medical resource conditions and residents seeking medical treatment, with which the empirical research on the implementation effect of the medical and health system reform in all regions of China is conducted.

\subsection{Data Source}

The samples in this paper are 31 provinces, municipalities and autonomous regions of China, while the empirical data comes from China Statistical Yearbook 2014 and China Health Statistical Yearbook 2014.

The dimensions of different indexes are greatly different and cannot be directly used for the comprehensive evaluation. Therefore, the original data of each index needs to be nondimensionalized, which is done with the Z-score function of SPSS 17.0 in this paper. Besides, the eight indexes under the dimension of residents seeking medical treatment are low-priority indexes, so the reciprocal values of their original data are used for the empirical data analysis.

\subsection{Evaluation Methods and Models}

\subsubsection{Determination of the Evaluation Factor Set}

The first layer of the evaluation factor set is the evaluation criteria layer, that is, the overall objective layer, denoted as $\mathrm{X}=\left(\mathrm{X}_{1}, \mathrm{X}_{2}, \cdots, \mathrm{X}_{\mathrm{N}}\right)$; the second layer is the evaluation factor layer, which is the decomposition of the overall goal, and is denoted as $\mathrm{X}_{\mathrm{i}}=\left(\mathrm{X}_{\mathrm{i} 1}, \mathrm{X}_{\mathrm{i} 2}, \cdots, \mathrm{X}_{\mathrm{iN}}\right)$; and the third layer is the evaluation index layer, which is composed of statistical indexes that reflect the evaluation objectives, and is denoted as $\mathrm{X}_{\mathrm{ik}}=\left(\mathrm{X}_{\mathrm{ik} 1}, \mathrm{X}_{\mathrm{ik} 2}, \cdots, \mathrm{X}_{\mathrm{ikm}}\right)$.

\subsubsection{Determination of Weight}

In order to eliminate the effect of subjective factors, factor analysis and AHP are used to determine the index weights [5] The factor analysis is used to determine the weights of the second- and third-grade indexes. First, the factor analysis is performed on the nondimensionalized indexes. Following the principle that the eigenvalue is greater than 1, the varimax orthogonal rotation method is used to rotate the factor load matrix to extract the primary factors in the three layers of social and economic conditions, medical resource conditions and residents seeking medical treatment. Then, the original indexes obtained are unitized by the load vector of each primary factor, and the weight vectors of indexes of the three grades in the index system can be obtained. Afterwards, the extracted primary factors are used as the second-grade indexes of the index system, and are unitized based on their contribution to higher-grade indexes, so as to obtain the weight vectors of second-grade indexes. The weights of the first-grade indexes are determined with AHP in the following steps:

1) Construct a pairwise comparison judgment matrix

The pairwise comparative judgment matrix of AHP reflects the relationships between factors with hierarchical structures, and gives a scale based on the importance of the measured objectives. If the importance of factor $i$ and factor $j$ is in the proportion of $a_{i j}$, the importance of factor $j$ and factor $i$ is in the proportion of $a_{i j}=\frac{1}{a_{i j}}$.

Table 1. Standard Table for Comparing Scores at Different Levels.

\begin{tabular}{lll}
\hline Scale & Relative importance & Notes \\
\hline 1 & Equally important & The two have the same contribution to the goal \\
3 & Slightly more important & One evaluation is slightly more favorable than the other one based on experience \\
5 & Fundamentally important & One evaluation is more favorable than the other one based on experience \\
7 & Really important & One evaluation is more favorable than the other one, which is proved \\
9 & Absolutely important & Obvious degree of importance \\
$2,4,6,8$ & Indicate the median values of the adjacency determinations above \\
\hline
\end{tabular}

2) Calculation Consistency Index:

The CI (Consistency Index) of the judgment matrix is: $\mathrm{CI}=\frac{\lambda_{\max }-\mathrm{n}}{\mathrm{n}-1}$

The greater the value of $\mathrm{CI}$, the greater the deviation of the judgment matrix from the complete consistency, while the smaller the value of $\mathrm{CI}$, the closer the judgment matrix to complete consistency.

3) RI is obtained based on the order look up table of the judgment matrix. See Table 2 for the RI (Random Index).

Table 2. RI Value Table.

\begin{tabular}{lllllllllll}
\hline Matrix order & $\mathbf{1}$ & $\mathbf{2}$ & $\mathbf{3}$ & $\mathbf{4}$ & $\mathbf{5}$ & $\mathbf{6}$ & $\mathbf{7}$ & $\mathbf{8}$ & $\mathbf{9}$ & $\mathbf{1 0}$ \\
\hline $\mathrm{RI}$ & 0.00 & 0.00 & 0.58 & 0.90 & 1.12 & 1.24 & 1.32 & 1.41 & 1.45 & 1.49 \\
\hline
\end{tabular}

The relative consistency index can be calculated as: $\mathrm{CR}=\mathrm{CI} / \mathrm{RI}$ (When $\mathrm{CR} \leq 0.1$, the judgment matrix is considered to meet the conditions of consistency check)

4) By calculating the maximum eigenvalues of the judgment matrix and unitizing the corresponding eigenvectors, the weight vectors corresponding to the first-grade indexes can be obtained.

Here, the weight vectors of the first-grade indexes are denoted as $A=\left(a_{1}, a_{2}, \cdots, a_{n}\right)$, those of the second-grade indexes $A_{i}=\left(a_{i 1}, a_{i 2}, \cdots, a_{i N}\right)$, and those of the third-grade indexes 
$\mathrm{A}_{\mathrm{ik}}=\left(\mathrm{a}_{\mathrm{ik} 1}, \mathrm{a}_{\mathrm{ik} 2}, \cdots, \mathrm{a}_{\mathrm{ikm}}\right)$, wherein $0<a_{\mathrm{n}}, \mathrm{a}_{\mathrm{iN}}, \mathrm{a}_{\mathrm{ikm}}<1$, and $\sum_{\mathrm{i}=1}^{\mathrm{n}} \mathrm{a}_{\mathrm{i}}=\sum_{\mathrm{k}=1}^{\mathrm{N}} \mathrm{a}_{\mathrm{ik}}=\sum_{\mathrm{j}=1}^{\mathrm{m}} \mathrm{a}_{\mathrm{ikj}}=1$.

\subsubsection{Determination of Evaluation Grades and Membership Functions}

With 5 evaluation grades, the effect of the reform of the medical and health system in each region can be better compared. In this paper, the change intervals of the sample index data are divided based on the mean values of the sample index data to achieve more uniform distribution of the sample data. Given there are $\mathrm{n}$ sample data $\mathrm{k}_{1}, \mathrm{k}_{2}, \cdots, \mathrm{k}_{\mathrm{n}}$ corresponding to each third-grade index $X_{i}$, $d_{1}, d_{2}, d_{3}, d_{4}, d_{5}$ are the level values of five evaluation grades, i.e., Very Poor, Poor, Average, Good, Very Good, then: the level value of Grade Very Poor is $\mathrm{d}_{1}=\min \left(\mathrm{k}_{1}, \mathrm{k}_{2}, \cdots, \mathrm{k}_{\mathrm{n}}\right)$; that of Grade Poor $\mathrm{d}_{2}=\frac{1}{\mathrm{~s}_{\text {num }}} \sum_{\mathrm{i}=1}^{\mathrm{S}_{\text {num }}} \mathrm{K}_{\mathrm{s}}$; that of Grade Average $\mathrm{d}_{3}=\frac{1}{\mathrm{n}} \sum_{\mathrm{i}=1}^{\mathrm{n}} \mathrm{K}_{\mathrm{n}}$; that of Grade Good $\mathrm{d}_{4}=$ $\frac{1}{\mathrm{l}_{\text {num }}} \sum_{\mathrm{i}=1}^{\mathrm{l}_{\text {num }}} \mathrm{K}_{\mathrm{l}}$; that of Grade Very Good $\mathrm{d}_{5}=\max \left(\mathrm{k}_{1}, \mathrm{k}_{2}, \cdots, \mathrm{k}_{\mathrm{n}}\right)$, wherein $\mathrm{K}_{\mathrm{s}}$ represents the sample data below the level value of Grade Average $d_{3}$ among all sample data, with $S_{\text {num }}$ in total; while $K_{l}$ represents that above $d_{3}$, with $l_{\text {num }}$ in total. For convenient calculation, the membership functions $X_{i}^{(j)}$ corresponding to Grade $\mathrm{V}_{\mathrm{j}}$ (Very Poor, Poor, Average, Good, Very Good) $(\mathrm{j}=$ $1,2,3,4,5)$ are established separately.

(1) The index $X_{i}$ is the member of the membership function for low grade level.

$$
X_{i}^{(1)}=\left\{\begin{array}{cc}
1 & x=d_{1} \\
\frac{d_{2}-x}{d_{2}-d_{1}} & d_{1}<x<d_{2} \\
0 & \text { Others }
\end{array}\right.
$$

(2) The index $X_{i}$ is the member of the membership function for lower grade level.

$$
X_{i}^{(2)}=\left\{\begin{array}{cc}
0 & \text { Others } \\
\frac{d_{3}-x}{d_{3}-d_{2}} & d_{2}<x<d_{3} \\
\frac{x-d_{1}}{d_{2}-d_{1}} & d_{1}<x<d_{2} \\
1 & x=d_{2}
\end{array}\right.
$$

(3) The index $X_{i}$ is the member of the membership function for average grade level.

$$
X_{i}^{(3)}=\left\{\begin{array}{cc}
0 & \text { Others } \\
\frac{d_{4}-x}{d_{4}-d_{3}} & d_{3}<x<d_{4} \\
\frac{x-d_{2}}{d_{3}-d_{2}} & d_{2}<x<d_{3} \\
1 & x=d_{3}
\end{array}\right.
$$

(4) The index $X_{i}$ is the member of the membership function for higher grade level.

$$
X_{i}^{(4)}=\left\{\begin{array}{cc}
0 & \text { Others } \\
\frac{d_{5}-x}{d_{5}-d_{4}} & d_{4}<x<d_{5} \\
\frac{x-d_{3}}{d_{4}-d_{3}} & d_{3}<x<d_{4} \\
1 & x=d_{4}
\end{array}\right.
$$

(5) The index $X_{i}$ is the member of the membership function for high grade level.

$$
X_{i}^{(5)}=\left\{\begin{array}{cc}
1 & x=d_{5} \\
\frac{x-d_{4}}{d_{5}-d_{4}} & d_{4}<x<d_{5} \\
0 & \text { Others }
\end{array}\right.
$$

The fuzzy set that maps the object to be evaluated to $\mathrm{V}_{\mathrm{j}}(\mathrm{j}=1,2,3,4,5)$ by means of the membership function on each evaluation index is denoted as $\left(r_{i k j 1}, r_{i k j 2}, \cdots, r_{i k j p}\right)$, so the evaluation matrix of the second-grade index can be expressed as $\mathrm{R}_{\mathrm{ik}}=\left(\begin{array}{cccc}\mathrm{r}_{\mathrm{ik} 11} & \mathrm{r}_{\mathrm{ik} 12} & \cdots & \mathrm{r}_{\mathrm{ik} 1 \mathrm{p}} \\ \vdots & \vdots & \vdots & \vdots \\ \mathrm{r}_{\mathrm{ikj} 1} & \mathrm{r}_{\mathrm{ikj} 2} & \cdots & \mathrm{r}_{\mathrm{ikjp}}\end{array}\right)$.

\subsubsection{Multi-level Comprehensive Evaluation Model}

The preliminary comprehensive evaluation is the comprehensive evaluation of $\mathrm{m}$ factors of each $\mathrm{X}_{\mathrm{ik}}=$ $\left(\mathrm{X}_{\mathrm{ik1}}, \mathrm{X}_{\mathrm{ik} 2}, \cdots, \mathrm{X}_{\mathrm{ikm}}\right)$ based on initial models, which obtains the membership grade vector $\mathrm{B}_{\mathrm{ik}}=\mathrm{A}_{\mathrm{ik}}{ }^{\circ} \mathrm{R}_{\mathrm{ik}}=\left(\begin{array}{llllll}\mathrm{b}_{\mathrm{ik} 1} & \mathrm{~b}_{\mathrm{ik} 2} & \mathrm{~b}_{\mathrm{ik} 3} & \mathrm{~b}_{\mathrm{ik} 4} & \mathrm{~b}_{\mathrm{ik} 5}\end{array}\right)$ of $\mathrm{X}_{\mathrm{ik}}$. Then a second-grade evaluation is performed on $X_{i}=$ $\left(X_{i 1}, X_{i 2}, \cdots, X_{i N}\right)$ using the membership grade vector $B_{i k}$ of each second-grade index $X_{i k}$, so as to obtain the membership grade vector $B_{i}=A_{i}{ }^{\circ} R_{i}=\left(\begin{array}{lllll}b_{i 1} & b_{i 2} & b_{i 3} & b_{i 4} & b_{i 5}\end{array}\right)$ of the first-grade index $X_{i}$. Finally, the total goal membership degree vector $B=A^{\circ} R=A^{\circ}\left(\begin{array}{c}B_{1} \\ B_{2} \\ \vdots \\ B_{N}\end{array}\right)=\left(\begin{array}{lllll}b_{1} & b_{2} & b_{3} & b_{4} & b_{5}\end{array}\right)$ of the total goal $\mathrm{X}=\left(\mathrm{X}_{1}, \mathrm{X}_{2}, \cdots, \mathrm{X}_{\mathrm{N}}\right)$ is obtained.

In order to highlight the differences between grades, the scores of the Grades I, II, III, IV, and V are set as 1, 4, 9, 16 and 25. Let $\gamma=\left(\begin{array}{lllll}1 & 4 & 9 & 16 & 25\end{array}\right)$, then the total evaluation score of the medical and health system reform in different regions can be obtained: Score $=\mathrm{B} \cdot \gamma^{\mathrm{T}}$.

\section{Empirical Results}

The following results are obtained according to the fuzzy comprehensive evaluations of the effect of the medical and health system reform in 31 provinces, autonomous regions and municipalities in China.

\subsection{Index System and Weights}

With the index system hierarchicalized and index weights determined, the index system obtained is shown in the following table: 
Table 3. The Evaluation Index System and Weights of the Medical and Health System Reform.

\begin{tabular}{|c|c|c|c|c|c|}
\hline $\begin{array}{l}\text { First-grade } \\
\text { indexes }\end{array}$ & $\begin{array}{l}\text { Weights of } \\
\text { first-grade indexes }\end{array}$ & $\begin{array}{l}\text { Second-grade } \\
\text { indexes }\end{array}$ & $\begin{array}{l}\text { Weights of } \\
\text { second-grade indexes }\end{array}$ & Third-grade indexes & $\begin{array}{l}\text { Weights of } \\
\text { third-grade indexes }\end{array}$ \\
\hline \multirow{11}{*}{$\begin{array}{l}\text { Social and } \\
\text { economic } \\
\text { conditions } \\
\mathrm{X}_{1}\end{array}$} & \multirow{11}{*}{0.105} & \multirow{7}{*}{$\begin{array}{l}\text { Economic } \\
\text { level } \mathrm{X}_{11}\end{array}$} & \multirow{7}{*}{0.613} & Local fiscal revenue (in 100 million yuan) $\mathrm{X}_{111}$ & 0.119 \\
\hline & & & & General budget revenue (in 100 million yuan) $\mathrm{X}_{112}$ & 0.117 \\
\hline & & & & Per capita fiscal revenue (yuan) $\mathrm{X}_{113}$ & 0.156 \\
\hline & & & & Per capita GDP (yuan) $\mathrm{X}_{114}$ & 0.156 \\
\hline & & & & $\begin{array}{l}\text { Per capita disposable income of urban residents } \\
\text { (yuan) } \mathrm{X}_{115}\end{array}$ & 0.157 \\
\hline & & & & $\begin{array}{l}\text { Per capita net income of rural residents } \\
\text { (yuan) } X_{116}\end{array}$ & 0.158 \\
\hline & & & & Per capita funding of NCMS (yuan) $\mathrm{X}_{117}$ & 0.137 \\
\hline & & \multirow{4}{*}{$\begin{array}{l}\text { Social } \\
\text { Security } \mathrm{X}_{12}\end{array}$} & \multirow{4}{*}{0.387} & $\begin{array}{l}\text { Number of rural residents participating in NCMS } \\
(10,000) \mathrm{X}_{121}\end{array}$ & 0.271 \\
\hline & & & & $\begin{array}{l}\text { Number of urban residents participating in MIUR } \\
(10,000) X_{122}\end{array}$ & 0.216 \\
\hline & & & & $\begin{array}{l}\text { Number of urban workers participating in MIUR } \\
(10,000) \mathrm{X}_{123}\end{array}$ & 0.216 \\
\hline & & & & Total population at the end of year $(10,000) \mathrm{X}_{124}$ & 0.297 \\
\hline \multirow{6}{*}{$\begin{array}{l}\text { Medical } \\
\text { resource } \\
\text { level } \mathrm{X}_{2}\end{array}$} & \multirow{6}{*}{0.258} & \multirow{2}{*}{$\begin{array}{l}\text { Financial } \\
\text { investment in } \\
\text { medical and } \\
\text { health } \\
\text { services } \mathrm{X}_{21}\end{array}$} & \multirow{2}{*}{0.701} & $\begin{array}{l}\text { Proportion of medical \& health expenditure in } \\
\text { public finance expenditure }(\%) X_{211}\end{array}$ & 0.489 \\
\hline & & & & $\begin{array}{l}\text { Proportion of financial subsidy in total revenue of } \\
\text { medical and health institutions (\%) } \mathrm{X}_{212}\end{array}$ & 0.511 \\
\hline & & \multirow{4}{*}{$\begin{array}{l}\text { Provision of } \\
\text { medical } \\
\text { services } \mathrm{X}_{22}\end{array}$} & \multirow{4}{*}{0.295} & $\begin{array}{l}\text { The proportion of medical service providers' } \\
\text { investment in fiscal expenditure in the medical and } \\
\text { health system (\%) } X_{221}\end{array}$ & 0.241 \\
\hline & & & & Number of medical workers per 1,000 people $\mathrm{X}_{222}$ & 0.260 \\
\hline & & & & $\begin{array}{l}\text { Number of licensed (assistant) physicians per } \\
1,000 \text { people } X_{223}\end{array}$ & 0.258 \\
\hline & & & & $\begin{array}{l}\text { Number of general practitioners per } 10,000 \\
\text { people } X_{224}\end{array}$ & 0.241 \\
\hline \multirow{8}{*}{$\begin{array}{l}\text { Residents } \\
\text { seeking } \\
\text { medical } \\
\text { treatment } \\
\mathrm{X}_{3}\end{array}$} & \multirow{8}{*}{0.637} & \multirow{3}{*}{$\begin{array}{l}\text { Hospitalization } \\
\mathrm{X}_{31}\end{array}$} & \multirow{3}{*}{0.428} & $\begin{array}{l}\text { Number of outpatient/emergency admissions per } \\
100 \text { people } X_{311}\end{array}$ & 0.318 \\
\hline & & & & Hospitalization rate of residents (\%) $\mathrm{X}_{312}$ & 0.427 \\
\hline & & & & Average length of stay $X_{313}$ & 0.255 \\
\hline & & \multirow{3}{*}{$\begin{array}{l}\text { Medical } \\
\text { expenses } \mathrm{X}_{32}\end{array}$} & \multirow{3}{*}{0.292} & Average hospital visits of residents $\mathrm{X}_{321}$ & 0.304 \\
\hline & & & & $\begin{array}{l}\text { Average outpatient medical expenses per } \\
\text { person/time (yuan) } X_{322}\end{array}$ & 0.348 \\
\hline & & & & $\begin{array}{l}\text { Per capita medical expenses of inpatients } \\
\text { (yuan) } X_{323}\end{array}$ & 0.348 \\
\hline & & \multirow{2}{*}{$\begin{array}{l}\text { Medical } \\
\text { burden } X_{33}\end{array}$} & \multirow{2}{*}{0.280} & $\begin{array}{l}\text { Proportion of urban residents' health care } \\
\text { expenditure (\%) } X_{3311}\end{array}$ & 0.508 \\
\hline & & & & $\begin{array}{l}\text { Proportion of rural residents' health care } \\
\text { expenditure (\%) } X_{332}\end{array}$ & 0.492 \\
\hline
\end{tabular}

\subsection{Results of Fuzzy Comprehensive Evaluation}

The membership degree vectors of the total goals obtained in each region at the five evaluation grades are shown in Table 4, and the comprehensive score and ranking of each region are calculated based on the scores 1, 4, 9, 16 and 25 of the five grades.

Table 4. The Membership Degree Vectors at Five Evaluation Grades and Comprehensive Score of Each Region.

\begin{tabular}{llllllll}
\hline & $\mathbf{b}_{\mathbf{1}}$ & $\mathbf{b}_{\mathbf{2}}$ & $\mathbf{b}_{\mathbf{3}}$ & $\mathbf{b}_{\mathbf{4}}$ & $\mathbf{b}_{\mathbf{5}}$ & Comprehensive Score & Ranking \\
\hline Beijing & {$[0.273$} & 0.139 & 0.288 & 0.104 & $0.195]$ & 9.976 & 6 \\
Tianjin & {$[0.178$} & 0.382 & 0.126 & 0.202 & $0.092]$ & 8.542 & 17 \\
Hebei & {$[0.098$} & 0.344 & 0.335 & 0.150 & $0.071]$ & 8.691 & 16 \\
Shanxi & {$[0.052$} & 0.343 & 0.377 & 0.181 & $0.046]$ & 8.861 & 14 \\
Inner Mongolia & {$[0.065$} & 0.393 & 0.274 & 0.262 & $0.006]$ & 8.449 & 18 \\
Liaoning & {$[0.222$} & 0.366 & 0.309 & 0.102 & $0.000]$ & 6.114 & 30 \\
Jilin & {$[0.168$} & 0.266 & 0.347 & 0.202 & $0.016]$ & 7.994 & 22 \\
Heilongjiang & {$[0.177$} & 0.455 & 0.275 & 0.036 & $0.057]$ & 6.467 & 28 \\
Shanghai & {$[0.228$} & 0.226 & 0.173 & 0.123 & $0.249]$ & 10.879 & 4 \\
Jiangsu & {$[0.079$} & 0.310 & 0.414 & 0.174 & $0.023]$ & 8.396 & 19 \\
Zhejiang & {$[0.061$} & 0.245 & 0.286 & 0.364 & $0.042]$ & 10.504 & 5 \\
Anhui & {$[0.060$} & 0.412 & 0.238 & 0.231 & $0.059]$ & 9.009 & 13 \\
\hline
\end{tabular}




\begin{tabular}{|c|c|c|c|c|c|c|c|}
\hline & $\mathbf{b}_{1}$ & $\mathbf{b}_{2}$ & $\mathbf{b}_{3}$ & $\mathbf{b}_{4}$ & $\mathbf{b}_{5}$ & Comprehensive Score & Ranking \\
\hline Fujian & {$[0.004$} & 0.156 & 0.474 & 0.257 & $0.107]$ & 11.707 & 2 \\
\hline Jiangxi & {$[0.109$} & 0.279 & 0.230 & 0.370 & $0.011]$ & 9.493 & 10 \\
\hline Shandong & {$[0.072$} & 0.360 & 0.367 & 0.182 & $0.018]$ & 8.184 & 21 \\
\hline Henan & {$[0.138$} & 0.371 & 0.259 & 0.111 & $0.120]$ & 8.739 & 15 \\
\hline Hubei & {$[0.109$} & 0.456 & 0.345 & 0.088 & $0.000]$ & 6.464 & 29 \\
\hline Hunan & {$[0.197$} & 0.344 & 0.227 & 0.212 & $0.019]$ & 7.492 & 25 \\
\hline Guangdong & {$[0.080$} & 0.132 & 0.383 & 0.287 & $0.098]$ & 11.338 & 3 \\
\hline Guangxi & {$[0.086$} & 0.339 & 0.300 & 0.177 & 0.097] & 9.406 & 11 \\
\hline Hainan & {$[0.044$} & 0.197 & 0.464 & 0.282 & $0.010]$ & 9.804 & 8 \\
\hline Chongqing & {$[0.090$} & 0.476 & 0.415 & 0.016 & $0.003]$ & 6.052 & 31 \\
\hline Sichuan & {$[0.081$} & 0.432 & 0.265 & 0.196 & $0.025]$ & 7.961 & 23 \\
\hline Guizhou & {$[0.266$} & 0.152 & 0.239 & 0.186 & $0.156]$ & 9.905 & 7 \\
\hline Yunnan & {$[0.037$} & 0.330 & 0.331 & 0.253 & $0.047]$ & 9.583 & 9 \\
\hline Tibet & {$[0.223$} & 0.106 & 0.053 & 0.124 & $0.493]$ & 15.458 & 1 \\
\hline Shanxi & {$[0.137$} & 0.304 & 0.412 & 0.141 & $0.006]$ & 7.457 & 26 \\
\hline Gansu & {$[0.168$} & 0.239 & 0.267 & 0.258 & $0.067]$ & 9.350 & 12 \\
\hline Qinghai & {$[0.140$} & 0.446 & 0.191 & 0.202 & $0.020]$ & 7.381 & 27 \\
\hline Ningxia & {$[0.074$} & 0.391 & 0.335 & 0.198 & $0.001]$ & 7.845 & 24 \\
\hline Xinjiang & {$[0.209$} & 0.347 & 0.126 & 0.273 & 0.044] & 8.203 & 20 \\
\hline
\end{tabular}

\section{Discussion}

According to the results of the comprehensive evaluation, we can find that the effect of the medical and health system reform is related to the level of local economic development to some extent, while Tibet is an exception. Tibet is sparsely populated, and the access to medical services is affected by traffic, geographical environment and low per capita income, so the medical and health care services are provided by the government. In economically developed regions such as Beijing, Shanghai and Guangdong, the medical resources are rich in terms of both financial investment in medical and health care and the provision of medical services. The higher comprehensive scores of these regions mainly come from higher-grade social and economic conditions and medical resources as well as lower grade for residents seeking medical treatment. However, it should be pointed out that as a large number of tertiary, Grade A hospitals gather in the economically developed regions, there is a "siphonic effect" on patients in surrounding areas [6-8], which in turn improves the low priority indexes of per capita hospital visits and per capita medical expense of local residents to some extent. So the evaluation results in these regions are suspected to be underrated. The evaluation results of economically underdeveloped regions such as Shanxi, Qinghai and Ningxia are ranked lower mainly due to the low membership grades of the social and economic conditions, those of Liaoning and Hubei the low level of medical resources, and those of Heilongjiang and Chongqing low membership grades in all the three dimensions. Therefore, both commonalities and differences exist in the results of comprehensive evaluation performance among different regions. However, as current status of medical services varies, the performance of medical services should be improved based on local conditions. In this paper, the following three suggestions are put forward:

First, more of the government's financial investment should be put into the remote areas where medical resources are not abundant and transportation is inconvenient, so as to provide basic and accessible medical services to the masses through giving subsidies to both supply and demand sides [9]. At the same time, promoting the reform of medical and health administration and supervision system, especially promoting the de-administration of public hospitals [10,11], is the key to solve this problem.

Second, as for the areas in shortage of medical resources, it is advised to attract and retain talented individuals by supporting the construction of hospital departments and improving the medical technologies of medical personnel, and encouraging investment of social capital into provision of medical services to create a competitive market environment, as only competition can improve the enthusiasm of medical staff and promote the improvement of the medical technologies, which will ultimately prevent local patients from outflowing and attract patients from the surrounding areas [12]. For regions with abundant medical resources, it is advised to reasonably reduce per capita medical expenses through controlling expenses by means of medical insurance, so as to reduce the economic burden of the masses.

Finally, reconstruct the medical insurance system. At present, the medical insurance fund does not have the nature of market players. The collection of medical insurance funds is carried out in accordance with administrative divisions and unified by the specialized agencies of the government departments. The administrative agencies that finance and pay for medical expenses have not play the role of the market players [13]. To a certain extent, the current medical system is not conducive to fairness and lack of efficiency. Reconstructing medical insurance system, grasping the quintessence of social insurance mode and controlling of medical expenses is the way out for solving the problem of seeing a doctor [14-15]; this is the right choice for the reform of the health care system. 


\section{Conclusion}

In summary, these results suggested that the effect of the medical and health system reform was related to the level of local economic development to some extent. In economically developed regions, the medical resources were rich in terms of both financial investments in medical care and the provision of medical services. However, in economically underdeveloped regions, neither medical resources nor financial subsidies were inadequate. This may aggravate the inequities of the use of health service. The reform of medical and health system should promote the flow of high-quality medical resources based on local actual conditions, so as to better meet people's needs for medical services.

\section{References}

[1] General Office of the State Council. "Implementation Opinions on Fully Promoting the Comprehensive Reform of All Public Hospitals at the County Level," April 2015.

[2] General Office of the State Council. "Guiding Opinions on Pilot Comprehensive Reform of Urban Public Hospitals," May 2015.

[3] Hu Shanlian (2010). Recommendations from International Organizations on China's Medical and Health System Reform Monitoring and Evaluation Framework. Chinese Journal of Health Policy 3(3), 4-6.

[4] Sun Xue (2012). Research on Establishment of the Mid-term Evaluation Index System for the Medical and Health System Reform in Chongqing. Chongqing: Chongqing Medical University, 19-21.

[5] Ren Yinghua, Qiu Bihuai, and Zhu Fengmei (2009). The Evaluation Index System for Modern Service Industry Development and Its Application. Journal of Statistics \& Decision 13, 31-33.
[6] Liu Junqiang, Liu Kai, Zeng Yi (2015). The mechanism of continuous growth of medical expenses. Social Sciences in China 8, 104-125.

[7] Du Chuang, Zhu Hengpeng (2016). The evolution logic of China's urban medical and health system. Social Sciences in China 8, 66-89.

[8] Zhu Hengpeng (2016). Encouraging the innovation of medical service mode and leading the reform of medical system. Journal of Financial Minds 1(1), 35-48.

[9] Zhu Fengmei (2016). Logical review on the Chinese medical and health system reform from 1985-2015. Chinese Health Economics35 (1), 5-9.

[10] Gu Xin (2018). From separation of management and operation to large part system: organizational guarantee for medical supply side reform. Journal of Governance Studies 2, 66-75.

[11] Yu Hui (2012). The reform of public hospitals: to be administrative or to be re-administrative. Journal of China Drug Store 5, 38.

[12] Gu Xin, Chen Siwei (2018). Private hospitals' market share in China's medical supply side. Journal of Xinjiang Normal University (Edition of Philosophy and Social Sciences), 39(4), 91-100.

[13] Chen Yongzheng, Li Shanshan, Huang Ying (2008). Several theoretical problems of Chinese medical reform. Journal of Finance \& Economics 1, 76-88.

[14] Yue Yi (2016). Research on medical insurance fee control mechanism under the background of marketization of drug prices. Journal of Management Observer 19, 73.

[15] Feng Jin, Yu Yangyang (2008). Medical and health system reform: marketization, incentive mechanism and the role of government. Journal of World Economic Papers 1, 1-13. 